\title{
Prevalence of urinary incontinence in women with spinal cord injury
}

\author{
Marlene Elmelund $\mathbb{D}^{1,2} \cdot$ Niels Klarskov ${ }^{2} \cdot$ Fin Biering-Sørensen ${ }^{1}$
}

Received: 14 March 2018 / Revised: 07 May 2018 / Accepted: 08 May 2018 / Published online: 12 June 2018

(c) International Spinal Cord Society 2018

\begin{abstract}
Study Design Cross-sectional study.

Objectives There is a knowledge gap on urinary incontinence in women with spinal cord injury. Hence, the aim of this study was to determine the prevalence and conditions associated with urinary incontinence in this population.

Setting Clinic for Spinal Cord Injuries, Rigshospitalet, Denmark.

Methods Women with a spinal cord injury between September 1999 and August 2016, who attended a consultation in our clinic during August 2010-August 2016, were included. Data were obtained from an electronic medical record database, in which standardized questionnaires were filled out by the treating physician during the consultation. Data regarding the injury, bladder function, mobility, spousal/cohabitation status, and quality of life were obtained from the most recently filledout questionnaires.

Results Of the 609 included women, 299 (49\%) experienced urinary incontinence: 27\% daily, 13\% weekly, and 9\% monthly. The odds of urinary incontinence increased if the woman used a wheelchair permanently (odds ratio (OR) 2.16, 95\% confidence interval (CI) 1.24-3.77), needed aids to walk (OR 1.73, 95\% CI 1.08-2.76), and if the woman's spousal/ cohabitation status was unmarried/not living with a partner (OR 1.60, 95\% CI 1.11-2.32). Conversely, the odds of urinary incontinence decreased if the woman used an indwelling catheter (OR 0.35, 95\% CI 0.18-0.67) compared with normal bladder-emptying method. Finally, incontinence was associated with decreased quality of life on the general, physical, and emotional domain.

Conclusions Urinary incontinence is a prevalent problem in women with spinal cord injury, affecting half of the population, and it is associated with impaired mobility, unmarried/non-cohabiting status, and reduced quality of life.
\end{abstract}

\section{Introduction}

Urinary incontinence (UI) frequently occurs as a consequence of neurogenic bladder dysfunction following a spinal cord injury (SCI) where neurogenic detrusor overactivity can result in reflex UI, acontractile detrusor can result in overflow UI, and underactive urethral sphincter and paralysis of the pelvic floor muscles can result in neurogenic stress UI [1]. Despite the abundance of many secondary health conditions following SCI, persons living with an SCI have ranked urinary problems as the most

Marlene Elmelund

marleneelmelund@hotmail.com

1 Clinic for Spinal Cord Injuries, Rigshospitalet, University of Copenhagen, Copenhagen, Denmark

2 Department of Obstetrics and Gynecology, Herlev and Gentofte Hospital, University of Copenhagen, Herlev, Denmark important health problem after injury $[2,3]$. The prevalence of UI in persons with SCI has been investigated in several studies with results varying from $34 \%$ in a Korean study [4] to $73 \%$ in a Turkish study [3]. However, all studies were conducted primarily in male SCI persons, with the largest female proportion being no more than $35 \%$ [2], and the majority was conducted in selected groups of persons with SCI.

The reported annual incidence rate of SCI varies from 10 to 58 per million for traumatic injuries $[5,6]$ and from 11 to 26 per million for non-traumatic injuries [7, 8], where women comprise $18-28 \%$ of the traumatic and approximately half of the non-traumatic SCI population $[5,8]$. Given the substantial proportion of women in the SCI population and the fact that there are fundamental anatomical and functional differences between the genders with a much higher prevalence of UI in women compared with men in general, there is a need for studies investigating UI and conditions regarding UI after SCI in women alone. 
Hence, the aim of this study was to investigate the prevalence of symptomatic UI and conditions associated with UI including quality of life (QoL) in women with an SCI.

\section{Methods}

\section{Study design and participants}

This cross-sectional database study was conducted in August 2016. The Clinic for Spinal Cord Injuries, Rigshospitalet is one of two national clinics where all persons with an SCI in Denmark are followed from the time of diagnosis. All patients are offered routine follow-up consultations every 2nd year lifelong. In this study, data were collected for all women registered in the Clinic for Spinal Cord Injuries, Rigshospitalet, Denmark with an SCI sustained during September 1999-August 2016, who attended a consultation in the clinic during August 2010-August 2016. During each consultation, the treating physician interviews the patient according to standardized questionnaires. If the physician had failed to fill out the standardized routine question regarding UI from the questionnaire International SCI Lower Urinary Tract Function Basic Data Set [9], the woman was excluded from the study.

\section{Data collection}

Data were obtained from the structured multidisciplinary electronic medical record database, spinal cord injury database (SCIBase) [10]. The SCIBase was established in September 1999 and contained internationally validated questionnaires and data, for example, International Standards for Neurological and Functional Classification of Spinal Cord Injury (ISNCSCI), 1996 [11] and Levi and Ertzgaard [12]. When updates of the ISNCSCI by Kirschblum et al. [13] and various International SCI Data Sets were developed, these were included as well. The injury was classified according to the International SCI Core Data Set after its publication in 2006 [14]. If symptoms had changed after the initial assessment, a reevaluation of the injury was normally conducted. In 2014, questions regarding non-traumatic etiology of injury was added, according to the simultaneously published dataset for non-traumatic SCI [15], and in August 2010, the International SCI Lower Urinary Tract Function Basic Data Set [9] was added to the database. Information regarding date, etiology, level, and completeness of injury by the ISNCSCI [13], bladder function, UI, and treatment of UI were collected from the most recently filled-out questionnaires. The definition of UI was based on the questionnaire from the International
SCI Lower Urinary Tract Function Basic Data Set [9]: "Any involuntary urine leakage (incontinence) within the last three months" with the following answer options: "Yes, average daily," "Yes, average weekly," "Yes, average monthly," "No," and "Not relevant". Women were divided into two groups, where the women answering yes to daily, weekly, or monthly UI were included in the UI group and the women answering no or not relevant were included in the no UI group. The primary bladder emptying methods were reported in the study in accordance with the International SCI Lower Urinary Tract Function Basic Data Set [9]. Normal bladder emptying method was defined as voluntary initiation of micturition without reflex stimulation or compression of the bladder, which does not presume entirely normal function. In addition to the data obtained from the SCIBase, information regarding treatments with vesical botulinum toxin injections was obtained from the Department of Urology, Rigshospitalet, where the treatments were carried out.

In April 2014, the International SCI Quality of Life Basic Data Set was added to the SCIBase [16]. The questionnaire was developed specifically to persons with an SCI and contains three questions regarding the satisfaction with (1) life as a whole, (2) physical health, and (3) psychological health, emotions, and mood in the past 4 weeks. Answers are given as numbers ranging from 0 to 10 , where 0 is completely dissatisfied and 10 is completely satisfied. The most recently filled-out questionnaire was obtained in this study.

Finally, the number of urinary tract infections within the last 12 months, smoking status, alcohol consumption, spousal/cohabitation status, and mobility were obtained from the most recently filled-out questionnaires. Spousal/ cohabitation status was defined as "Married/cohabiting partner" if the woman was married or living together with a partner and "Unmarried/no cohabiting partner" if the woman was unmarried, separated, or widowed and did not live with a partner. Mobility was defined as "Walks without walking aids" if the woman never used devices to walk, "Walks with walking aids" if the woman was able to walk with a walking frame, crutches, canes, or occasional used a wheelchair, and "Permanent wheelchair user" if the woman used a manual or electric wheelchair permanently.

To test the accuracy of the provided answers in the database, the answer "use of condom catheter/sheath" as collecting appliances for UI was evaluated.

\section{Statistical analysis}

Comparisons between groups in Tables 3 and 4 were conducted using Fisher's exact test for categorical variables. Student's $t$ tests were used for normally distributed 
continuous variables, and Mann-Whitney $U$ tests were used for non-normally distributed continuous variables. In Fig. 2, the differences in QoL scores according to UI frequencies were investigated using the non-parametric Kruskal-Wallis test. As age is known to increase the risk of UI in women [17], each covariate was adjusted for age in a bivariate logistic regression (Table 5). Second, a multivariate logistic regression analysis was conducted including the variables with $p<0.2$ in the bivariate logistic regression analyses. Model assumptions of linearity were tested for the quantitative variables by including a quadratic value of the variable in each model. All analyses were conducted using SAS version 7.1 (SAS Institute Inc., Cary, NC, USA), and a $p$ value $<0.05$ was considered statistically significant.

\section{Results}

\section{Study population}

Of the 733 eligible women identified, a total of 124 women were excluded due to missing data on the question

Table 1 Baseline characteristics

\begin{tabular}{|c|c|c|c|c|}
\hline Characteristics & Number & $\begin{array}{l}\text { Included women } \\
(n=609)\end{array}$ & Number & $\begin{array}{l}\text { Excluded women } \\
(n=124)\end{array}$ \\
\hline Mean age (years) & 609 & $53.9( \pm 19.7)^{*}$ & 80 & $60.1( \pm 20.3)^{*}$ \\
\hline Mean age at injury (years) & 529 & $42.2( \pm 23.8)^{*}$ & 88 & $52.1( \pm 23.9)^{*}$ \\
\hline Median follow-up (years) & 529 & $7.2(2.7-16.4)^{*}$ & 70 & $3.5(0.4-7.9)^{*}$ \\
\hline Etiology of injury & 440 & & 77 & \\
\hline Traumatic, sports & & $14(3 \%)$ & & 0 \\
\hline Traumatic, assault & & $2(0.5 \%)$ & & $1(1 \%)$ \\
\hline Traumatic, transport & & $35(8 \%)$ & & $8(10 \%)$ \\
\hline Traumatic, fall & & $53(12 \%)$ & & $9(12 \%)$ \\
\hline Traumatic, other cause & & $9(2 \%)$ & & $1(1 \%)$ \\
\hline Non-traumatic, congenital & & $57(13 \%)$ & & $6(8 \%)$ \\
\hline Non-traumatic, degenerative & & $97(22 \%)$ & & $24(31 \%)$ \\
\hline Non-traumatic, benign tumor & & $47(11 \%)$ & & $12(16 \%)$ \\
\hline Non-traumatic, malign. tumor & & $7(2 \%)$ & & 0 \\
\hline Non-traumatic, vascular & & $36(8 \%)$ & & $6(8 \%)$ \\
\hline Non-traumatic, infection & & $12(3 \%)$ & & $2(3 \%)$ \\
\hline Non-traumatic, other cause & & $71(16 \%)$ & & $8(10 \%)$ \\
\hline Neurological level of injury & 424 & & 86 & \\
\hline Cervical & & $193(46 \%)$ & & $42(49 \%)$ \\
\hline Thoracic & & $152(36 \%)$ & & $32(37 \%)$ \\
\hline Lumbar & & $69(16 \%)$ & & $10(12 \%)$ \\
\hline Sacral & & $10(2 \%)$ & & $2(2 \%)$ \\
\hline Completeness (AIS) & 403 & & 73 & \\
\hline A & & $30(7 \%)$ & & $4(6 \%)$ \\
\hline $\mathrm{B}$ & & $15(4 \%)$ & & $4(6 \%)$ \\
\hline $\mathrm{C}$ & & $39(10 \%)$ & & $13(18 \%)$ \\
\hline $\mathrm{D}$ & & $316(78 \%)$ & & $52(71 \%)$ \\
\hline $\mathrm{E}$ & & $3(1 \%)$ & & 0 \\
\hline Classification of injury by AIS and NLI & 403 & & 73 & \\
\hline AIS ABC, $\mathrm{C} 1-\mathrm{C} 8$ & & $26(6 \%)$ & & $9(12 \%)$ \\
\hline AIS ABC, Th1-S5 & & $58(14 \%)$ & & $12(16 \%)$ \\
\hline AIS D, any NLI & & $316(78 \%)$ & & $52(71 \%)$ \\
\hline AIS E & & $3(1 \%)$ & & 0 \\
\hline
\end{tabular}

AIS American Spinal Injury Association (ASIA) impairement scale, NLI neurological level of injury

Results are presented in mean $( \pm \mathrm{SD})$, median (interquartile range), or in total numbers $(\%)$

$* p<0.05$ 
Table 2 Missing data and time interval between answering of the urinary incontinence question and other questions

\begin{tabular}{|c|c|c|c|}
\hline Question & $\begin{array}{l}N \text { with missing } \\
\text { data }\end{array}$ & $\begin{array}{l}N \text { with deviation in time } \\
\text { from the UI answer }\end{array}$ & $\begin{array}{l}\text { Median (range) time } \\
\text { deviation in years }\end{array}$ \\
\hline \multicolumn{4}{|l|}{ Spinal cord injury characteristics } \\
\hline Neurological level of injury ${ }^{a}$ & $185(30 \%)$ & - & - \\
\hline Completeness of injury ${ }^{a}$ & $206(34 \%)$ & - & - \\
\hline $\begin{array}{l}\text { Traumatic vs. non-traumatic etiology of } \\
\text { injury }^{\mathrm{a}}\end{array}$ & $10(2 \%)$ & - & - \\
\hline Specified etiology of injury ${ }^{b}$ & $169(28 \%)$ & - & - \\
\hline \multicolumn{4}{|l|}{ Lower urinary tract } \\
\hline Any involuntary urine leakage (UI) ${ }^{\mathrm{c}}$ & NA & NA & NA \\
\hline Bladder emptying method ${ }^{\mathrm{c}}$ & $21(3 \%)$ & 0 & NA \\
\hline Self-supporting bladder empty & $29(5 \%)$ & 0 & NA \\
\hline $\begin{array}{l}\text { Awareness of the need to empty the } \\
\text { bladder }^{c}\end{array}$ & $92(15 \%)$ & 0 & NA \\
\hline Daily voluntary bladder emptyings ${ }^{\mathrm{c}}$ & $175(29 \%)$ & 0 & NA \\
\hline Collecting appliances for $\mathrm{UI}^{\mathrm{c}}$ & $156(26 \%)$ & 0 & NA \\
\hline Drugs for urinary tract in the last year ${ }^{c}$ & $74(12 \%)$ & 0 & NA \\
\hline Quality of life ${ }^{\mathrm{d}}$ & $361(59 \%)$ & $41(17 \%)$ & $-0.9(-2.0$ to 2.9$)$ \\
\hline $\begin{array}{l}\text { Treated urinary tract infections in the last } \\
\text { year }\end{array}$ & $164(27 \%)$ & $125(28 \%)$ & $-2.2(-9.8$ to 1.9$)$ \\
\hline Mobility & $31(5 \%)$ & $58(10 \%)$ & $-1.0(-5.1$ to 2.9$)$ \\
\hline Smoking status & $30(5 \%)$ & $102(18 \%)$ & $-1.3(-6.5$ to 2.9$)$ \\
\hline Alcohol consumption & $28(5 \%)$ & $92(16 \%)$ & $-1.2(-6.5$ to 2.9$)$ \\
\hline Spousal/cohabitation status & $26(4 \%)$ & $77(13 \%)$ & $-1.1(-5.1$ to 2.9$)$ \\
\hline
\end{tabular}

UI urinary incontinence, $S C I$ spinal cord injury, $N A$ not applicable

${ }^{a}$ According to International standards for neurological classification of spinal cord injury (revised 2011) [13], and International spinal cord injury core data Set [14]

${ }^{\mathrm{b}}$ According to International spinal cord injury data sets for non-traumatic spinal cord injury [15]

${ }^{\mathrm{c}}$ According to International spinal cord injury lower urinary tract function basic data set [9]

${ }^{\mathrm{d} A c c o r d i n g}$ to International spinal cord injury quality of life basic data set [16]

regarding UI. Hence, 609 women were included in the study. The excluded women did not differ in level, completeness, type, and etiology of injury compared with the included women. However, compared with the included women, the excluded women were significantly older at the last follow-up visit and at time of injury, and they had a significantly shorter median follow-up period (Table 1). The degree of missing data and the timeframe according to when the questionnaires were filled out are shown in Table 2.

\section{Prevalence of UI}

A total of 299 women (49\%) reported of symptomatic UI varying from daily to monthly. When divided by frequency, $166(27 \%)$ experienced UI daily, 79 (13\%) experienced UI weekly, and 54 (9\%) experienced UI monthly (Fig. 1). The answer "Not relevant" was applied in 12 women $(2 \%)$, of whom 9 used an indwelling catheter (5 suprapubic and 4 transurethral), 2 used clean intermittent catheterization, and

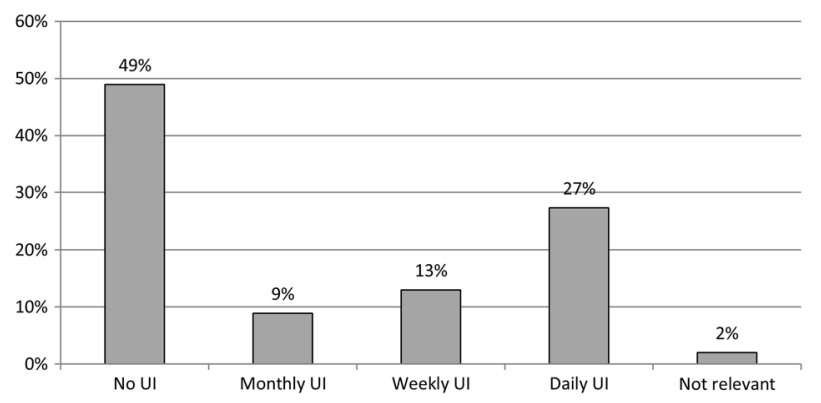

Fig. 1 Urinary incontinence within the last 3 months among the included women $(n=609)$. UI urinary incontinence

1 used an unknown bladder emptying method. To the question regarding collecting appliances of UI, 11 of the 12 women did not use diapers/pads, and the 12 women were included in the continent group in the following analysis.

There were no positive answers to the question "use of condom catheter/sheath" as collecting appliances for UI among the included women. 
Table 3 Characteristics associated with frequency of urinary incontinence

\begin{tabular}{|c|c|c|c|c|}
\hline Characteristics & Number & No UI & Weekly/monthly UI & Daily UI \\
\hline Mean age (years) & 609 & $52.1(50.0-54.3)$ & $50.6(47.3-53.9)$ & $59.9(56.9-62.8)^{*}$ \\
\hline Mean age at injury (years) & 529 & $40.7(37.9-43.4)$ & $36.1(31.8-40.4)$ & $49.6(45.8-53.5)^{*}, * *$ \\
\hline Median follow-up (years) & 529 & $6.5(2.7-14.7)$ & $9.6(5.0-21.6)^{* * *}$ & $6.6(2.1-13.8)^{*}$ \\
\hline Type of injury & 599 & & & \\
\hline Traumatic & & $94(31 \%)$ & $34(26 \%)$ & $41(25 \%)$ \\
\hline Non-traumatic & & $213(69 \%)$ & $97(74 \%)$ & $120(75 \%)$ \\
\hline Etiology of injury & 440 & & & \\
\hline Spinal cord injury & & $197(87 \%)$ & $80(79 \%)$ & $106(94 \%)^{*}$ \\
\hline Myelomeningocele & & $29(13 \%)$ & $21(21 \%)$ & $7(6 \%)^{*}$ \\
\hline Classification of injury by AIS and NLI & 403 & & & \\
\hline AIS ABC, C1-C8 & & $16(8 \%)$ & $3(4 \%)$ & $7(7 \%)$ \\
\hline AIS ABC, Th1-S5 & & $30(14 \%)$ & $15(18 \%)$ & $13(12 \%)$ \\
\hline AIS DE, any NLI & & $167(78 \%)$ & $67(79 \%)$ & $85(81 \%)$ \\
\hline Level of Injury & 424 & & & \\
\hline Tetraplegia & & $109(49 \%)$ & $34(39 \%)$ & $50(44 \%)$ \\
\hline Paraplegia & & $115(51 \%)$ & $53(61 \%)$ & $63(56 \%)$ \\
\hline Primary bladder emptying method & 588 & & & \\
\hline Normal & & $163(54 \%)$ & $61(48 \%)$ & $93(58 \%) * *$ \\
\hline $\mathrm{IC}^{\mathrm{a}}$ & & $67(22 \%)$ & $37(29 \%)$ & $33(21 \%)^{* *}$ \\
\hline Indwelling catheter ${ }^{\mathrm{b}}$ & & $51(17 \%)$ & $15(12 \%)$ & $12(8 \%)^{* *}$ \\
\hline Other method(s) ${ }^{\mathrm{c}}$ & & $20(7 \%)$ & $15(12 \%)$ & $21(13 \%)^{* *}$ \\
\hline Mobility & 578 & & & \\
\hline Walks without aids & & $99(34 \%)$ & $34(26 \%)$ & $31(20 \%) * *$ \\
\hline Walks with aids & & $104(35 \%)$ & $51(40 \%)$ & $73(47 \%)^{* *}$ \\
\hline Wheelchair user & & $91(31 \%)$ & $44(34 \%)$ & $51(33 \%) * *$ \\
\hline Spousal/cohabitation status & 583 & & & \\
\hline Married/cohabiting partner & & $163(55 \%)$ & $60(46 \%)$ & $71(46 \%)$ \\
\hline Unmarried/no cohabiting partner & & $136(45 \%)$ & $70(54 \%)$ & $83(54 \%)$ \\
\hline Smoking status & 579 & & & \\
\hline Never & & $157(53 \%)$ & $71(56 \%)$ & $83(54 \%)$ \\
\hline Former smoker & & $82(28 \%)$ & $29(23 \%)$ & $40(26 \%)$ \\
\hline Current smoker & & $59(20 \%)$ & $27(21 \%)$ & $31(20 \%)$ \\
\hline Alcohol consumption & 581 & & & \\
\hline$\geq 5$ units per day & & $1(0.3 \%)$ & 0 & $1(1 \%)$ \\
\hline $1-4$ units per day & & $23(8 \%)$ & $12(9 \%)$ & $17(11 \%)$ \\
\hline Not daily & & $240(80 \%)$ & $102(80 \%)$ & $107(70 \%)$ \\
\hline Never & & $36(12 \%)$ & $14(11 \%)$ & $28(18 \%)$ \\
\hline
\end{tabular}

Results are presented in mean $( \pm \mathrm{SD})$, median (interquartile range), and numbers $(\%)$

UI urinary incontinence, IC intermittent catheterization, AIS American Spinal Injury Association (ASIA) impairement scale, NLI neurological level of injury

*Significant difference between the daily UI group and the weekly/monthly UI group; **significant difference between the no UI group and the daily UI group; ***significant difference between the no UI group and the weekly/monthly group

${ }^{\mathrm{a}}$ Including self IC and IC by attendant

${ }^{\mathrm{b}}$ Including urethral and suprapubic indwelling catheter

${ }^{c}$ Including bladder expression, bladder reflex triggering, Bricker conduit, $\geq 2$ primary emptying methods, and other methods 
Table 4 Bladder characteristics according to urinary incontinence

\begin{tabular}{|c|c|c|c|c|c|}
\hline Characteristics & Number & UI & Number & No UI & $p$ value \\
\hline Primary bladder emptying method & 287 & & 301 & & - \\
\hline Normal voiding & & $154(54 \%)$ & & $163(54 \%)$ & \\
\hline Self IC & & $61(21 \%)$ & & $64(21 \%)$ & \\
\hline IC by attendant & & $9(3 \%)$ & & $3(1 \%)$ & \\
\hline Indwelling transurethral catheter & & $12(4 \%)$ & & $23(8 \%)$ & \\
\hline Indwelling suprapubic catheter & & $15(5 \%)$ & & $28(9 \%)$ & \\
\hline Voluntary reflex triggering & & $6(2 \%)$ & & 0 & \\
\hline Involuntary reflex triggering & & $4(1 \%)$ & & 0 & \\
\hline Bladder expression $^{\mathrm{a}}$ & & $7(2 \%)$ & & $5(2 \%)$ & \\
\hline Other method & & $3(1 \%)$ & & $4(1 \%)$ & \\
\hline$\geq 2$ primary emptying methods & & $16(5 \%)$ & & $11(4 \%)$ & \\
\hline Self-supporting bladder emptying & 285 & & 295 & & 0.7 \\
\hline Yes & & $233(82 \%)$ & & $246(83 \%)$ & \\
\hline No & & $52(18 \%)$ & & $49(17 \%)$ & \\
\hline Awareness of the need to empty the bladder ${ }^{\mathrm{b}}$ & 251 & & 266 & & 0.021 \\
\hline Yes, directly & & $180(72 \%)$ & & $189(71 \%)$ & \\
\hline Yes, indirectly & & $43(17 \%)$ & & $29(11 \%)$ & \\
\hline No & & $28(11 \%)$ & & $48(18 \%)$ & \\
\hline Median daily voluntary bladder emptyings & 221 & $7(6-8)$ & 213 & $6(5-7)$ & $<0.001$ \\
\hline Collecting appliances ${ }^{c}$ & 279 & & 174 & & \\
\hline Yes, diaper/pads & & $169(61 \%)$ & & $17(10 \%)$ & $<0.001$ \\
\hline Yes, ostomy bag & & 0 & & $7(4 \%)$ & 0.015 \\
\hline Yes, other methods & & $60(22 \%)$ & & $12(7 \%)$ & - \\
\hline No & & $54(19 \%)$ & & $141(81 \%)$ & $<0.001$ \\
\hline Drugs for urinary tract in last year ${ }^{c}$ & 269 & & 266 & & \\
\hline Yes, bladder relaxant drugs & & $37(14 \%)$ & & $19(7 \%)$ & 0.011 \\
\hline Yes, sphincter relaxant drugs & & $5(2 \%)$ & & $2(1 \%)$ & 0.3 \\
\hline Yes, antibiotics unspecified & & $107(40 \%)$ & & $90(34 \%)$ & 0.08 \\
\hline Prophylactic & & $17(6 \%)$ & & $19(7 \%)$ & 0.9 \\
\hline Treatment of urinary tract infection & & $91(34 \%)$ & & $76(29 \%)$ & 0.10 \\
\hline Yes, other & & $10(4 \%)$ & & $8(3 \%)$ & - \\
\hline No & & $130(48 \%)$ & & $157(59 \%)$ & 0.08 \\
\hline Vesical botulinum toxin injections ${ }^{\mathrm{d}}$ & & $28(10 \%)$ & & $18(7 \%)$ & 0.12 \\
\hline Treated urinary tract infections in last year & 229 & $1(0-3)$ & 216 & $1(0-2)$ & 0.7 \\
\hline
\end{tabular}

$U I$ urinary incontinence, $I C$ intermittent catheterization

ancluding Valsalvas manouvre and Credé

b"Yes, directly" refers to any kind of bladder sensation, "Yes, indirectly" refers to a nonspecific bladder sensation, for example, by abdominal fullness, sweating, or spasticity, and "No" refers to absent bladder sensation

${ }^{c}$ Each person can have more than one answer

${ }^{\mathrm{d}}$ Treatment with vesical botulinum toxin injections at any time

\section{Covariates associated with UI}

Differences between the groups of women with daily UI, weekly or monthly UI, and no UI are shown in Table 3. The women with daily UI were significantly older at follow-up, at the time of injury, and had a shorter follow-up period compared with the women with weekly/monthly UI. In addition, a larger proportion of women with myelomeningocele as etiology of injury experienced weekly/monthly UI instead of daily UI. When comparing the continent group with the weekly/monthly UI group, the groups only differed on median follow-up period, whereas the continent group and the daily UI group differed on mean age at injury, bladder emptying method, and mobility. 
Table 5 Risk of urinary incontinence in logistic regression analysis

\begin{tabular}{|c|c|c|c|c|c|}
\hline \multirow[t]{2}{*}{ Parameter } & \multirow[t]{2}{*}{ Number } & \multicolumn{2}{|l|}{ Bivariate $^{\mathrm{a}}$} & \multicolumn{2}{|l|}{ Multivariate $^{\mathrm{b}}$} \\
\hline & & OR $(95 \% \mathrm{CI})$ & $p$ value & OR $(95 \% \mathrm{CI})$ & $p$ value \\
\hline Age (per year) & 609 & $1.01(1.00-1.02)$ & $\mathbf{0 . 0 2 3} *$ & $1.01(1.00-1.02)$ & 0.06 \\
\hline Type of injury & 599 & & & & \\
\hline Traumatic & & 1.0 (ref.) & & 1.0 (ref.) & \\
\hline Non-traumatic & & $1.27(0.89-1.82)$ & 0.19 & $1.46(0.97-2.19)$ & 0.07 \\
\hline Primary bladder emptying method & 588 & & & & \\
\hline Normal & & 1.0 (ref.) & & 1.0 (ref.) & \\
\hline $\mathrm{IC}^{\mathrm{c}}$ & & $1.26(0.83-1.90)$ & 0.28 & $0.90(0.56-1.46)$ & 0.7 \\
\hline Indwelling catheter $^{\mathrm{d}}$ & & $0.49(0.29-0.83)$ & 0.008 & $0.35(0.18-0.67)$ & 0.002 \\
\hline Other method(s) ${ }^{\mathrm{e}}$ & & $1.81(1.00-1.02)$ & 0.05 & $1.99(1.02-3.87)$ & 0.044 \\
\hline Mobility & 578 & & & & \\
\hline Walks without aids & & 1.0 (ref.) & & 1.0 (ref.) & \\
\hline Walks with aids & & $1.64(1.07-2.52)$ & 0.022 & $1.73(1.08-2.76)$ & 0.022 \\
\hline Wheelchair user & & $1.43(0.92-2.24)$ & 0.11 & $2.16(1.24-3.77)$ & 0.007 \\
\hline Spousal/cohabitation status & 583 & & & & \\
\hline Married/cohabiting partner & & 1.0 (ref.) & & 1.0 (ref.) & \\
\hline Unmarried/no cohabiting partner & & $1.44(1.04-2.00)$ & $\mathbf{0 . 0 3 0}$ & $1.60(1.11-2.32)$ & 0.012 \\
\hline Smoking status & 579 & & & & \\
\hline Never & & 1.0 (ref.) & & 1.0 (ref.) & \\
\hline Former smoker & & $0.76(0.51-1.14)$ & 0.18 & $0.71(0.45-1.11)$ & 0.13 \\
\hline Current smoker & & $0.99(0.65-1.52)$ & 1.0 & $0.96(0.60-1.55)$ & 0.9 \\
\hline Alcohol consumption & 581 & & & & \\
\hline Not daily/never & & 1.0 (ref.) & & & \\
\hline$\geq 1$ unit per day & & $1.22(0.69-2.17)$ & 0.5 & & \\
\hline Classification of injury by AIS and NLI & 403 & & & & \\
\hline AIS DE, any NLI & & 1.0 (ref.) & & & \\
\hline AIS ABC, Th1-S5 & & $1.08(0.61-1.91)$ & 0.8 & & \\
\hline AIS ABC, C1-C8 & & $0.66(0.29-1.51)$ & 0.3 & & \\
\hline Etiology & 440 & & & & \\
\hline Spinal cord injury & & 1.0 (ref.) & & & \\
\hline Myelomeningocele & & $1.34(0.72-2.48)$ & 0.4 & & \\
\hline Follow-up & 609 & & & & \\
\hline$<1$ year & & 1.0 (ref.) & & & \\
\hline $1-9$ years & & $0.89(0.58-1.35)$ & 0.6 & & \\
\hline$\geq 10$ years & & $1.09(0.70-1.70)$ & 0.7 & & \\
\hline Age at injury (per year) & 529 & $1.00(0.98-1.01)$ & 0.5 & & \\
\hline
\end{tabular}

OR odds ratio, IC intermittent catheterization, AIS American Spinal Injury Association (ASIA) impairment scale, $N L I$ neurological level of injury *Univariate analysis

${ }^{a}$ Adjusted for age

${ }^{\mathrm{b}}$ Multivariate analysis including 521 women

'Including self IC and IC by attendant

${ }^{\mathrm{d}}$ Including urethral and suprapubic indwelling catheter

${ }^{\mathrm{e}}$ Including bladder expression, bladder reflex triggering, Bricker conduit, $\geq 2$ primary emptying methods, and other methods

The UI groups were pooled and compared with the continent group in Tables 4 and 5. A larger proportion of women in the UI group had indirect bladder sensation and a smaller proportion had no bladder sensation, the number of daily voluntary bladder emptyings was higher and more women used diapers/pads and bladder relaxant 


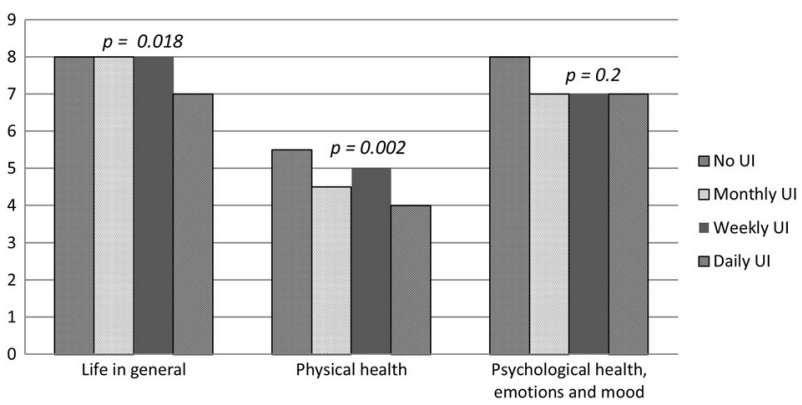

Fig. 2 Quality of life and frequency of urinary incontinence $(n=246)$. Women's satisfaction in the past 4 weeks, where 0 is completely dissatisfied and 10 is completely satisfied. UI urinary incontinence

drugs compared with the women in the no UI group (Table 4).

In the multivariate logistic regression analysis, the bladder emptying method, mobility, and spousal/cohabitation status were associated with UI (Table 5). Women were less likely to be incontinent if they used indwelling urethral or suprapubic catheter compared with women using normal bladder emptying method (OR 0.35, 95\% CI 0.18-0.67) and more likely to be incontinent if they used another method (reflex triggering/bladder expression/other methods) compared with women using normal bladder emptying method (OR 1.99, 95\% CI 1.02-3.87). Compared with women walking without devices, UI was more likely in women walking with aids (OR 1.73, 95\% CI 1.08-2.76) or women using a wheelchair (OR 2.16, 95\% CI 1.24-3.77). Finally, UI was associated with unmarried, separated, or widowed status compared with married women or women living together with a partner (OR 1.60, 95\% CI 1.11-2.32).

\section{QoL and UI}

The International SCI QoL Basic Data Set [16] was filled out by 246 women (40\%). Compared with the group of continent women $(n=128)$, the women with UI $(n=118)$ reported a lower median satisfaction score over the last 4 weeks with their life in general (7 (interquaritle range (IQR) 5-8) vs. 8 (IQR 6-9), $p=0.012$ ), with their physical health (5 (IQR 3-7) vs. 5.5 (IQR 4-8), $p=0.001$ ) and with their psychological health, emotions, and mood (7 (IQR 5-8) vs. 8 (IQR 5-9), $p=0.039$ ).

The median scores of the questionnaire according to the frequency of UI are shown in Fig. 2.

\section{Discussion}

In this large cross-sectional database study, we found that approximately half of the female SCI population experience symptomatic UI with the majority experiencing daily UI. UI was associated with impaired mobility, unmarried/noncohabiting status, use of non-indwelling catheter, and reduced QoL. A prevalence of $49 \%$ of whom the majority experience daily UI is surprisingly high given the fact that the included female population are already followed at a highly specialized SCI clinic offering regular follow-up visits every second year.

The prevalence of symptomatic UI in able-bodied westernized populations shows a vide variability with results varying from $25 \%$ to $46 \%$ [17-19], mainly due to differences in the definitions of UI, design of the study, and included study populations. Though the $49 \%$ prevalence of UI in women with SCI is not much higher than the reported prevalence of $46 \%$ in able-bodied women found in one study [19], the severity of UI in women with SCI differs from the general female population. In a Norwegian questionnaire-based study defining UI as "any" UI with no time limits, only $20 \%$ of the incontinent women experienced daily UI compared with $56 \%$ in our study [17]. In addition, the able-bodied populations in the questionnaire-based prevalence studies are communitydwelling women who have not necessarily consulted a medical doctor with their UI problems, whereas the SCI women in this study were already followed at a highly specialized clinic that offers treatment of UI and bladder emptying problems.

To date, the prevalence of UI in SCI persons has only been investigated in studies including both men and women, where women comprise a minority of the population. Hansen et al. [20] investigated the prevalence of UI using the same definition of UI as in the present study. In 236 traumatic SCI individuals, of whom $18 \%$ were women, the overall self-reported prevalence of UI was $43 \%$ and the prevalence of daily UI was $20 \%$, which is a little lower than in the present study [20]. Two other studies investigating UI in mixed-gender SCI populations found that women had the highest prevalence of UI [3, 21].

We found no association between UI and level or completeness of injury, type of injury, age at injury, and followup period after injury in the logistic regression analysis, which is in accordance with most other studies [2, 3]. Though no association was found between the American Spinal Injury Association (ASIA) impairement scale (AIS) score and UI in our study, the odds of UI increased significantly with impaired mobility in the multivariate analysis. It has previously been proposed that functional impairment can lead to UI due to difficulties in getting to the bathroom and removing clothes [22]. In terms of etiology of injury, myelomeningocele was associated with weekly/monthly UI compared with daily UI, which could be explained by the fact that the women with myelomeningocele were younger at follow-up than the women with 
non-myelomeningocele in this study (median age 26 years vs. 61 years, respectively).

Further, UI was less likely to occur if the woman used an indwelling catheter compared with normal bladder emptying method, but due to the cross-sectional design of this study, the causality cannot be established. The association between UI and unmarried/non-cohabitation status and reduced QoL on the general, physical, and emotional domain underlines the impact of UI on the woman's general life situation and well-being. The QoL questionnaire was not specific to the symptoms of UI, but was developed as a tool to measure the general QoL in persons with SCI, who face a large variability of complications following an SCI. The fact that UI is significantly associated with reduced QoL on this general QoL questionnaire underlines the impact of UI in this population. The results are in agreement with the study by Liu et al. [23], showing a reduced QoL on the mental, emotional, and social domain in incontinent SCI persons. In addition, UI has been reported as a major physical problem associated with sexual activity in SCI persons [24] and it is associated with depression and loneliness in neurologically intact persons [25], which could explain the association between UI and unmarried/non-cohabitation status found in this study.

Fifteen percent of the study population had received treatment for neurogenic detrusor overactivity $(9 \%$ used bladder relaxant drugs and $8 \%$ had received vesical botulinum toxin injection previously). The limited use could be explained by the fact that a large proportion of the female incontinence is caused by stress UI, which would require other treatment options that were not registered in this study.

To date, this is the largest study investigating the prevalence of UI in SCI persons, and the first to investigate UI in women alone. It is a strength that data were obtained from a database including only internationally standardized SCI-specific questionnaires, which makes the study results robust and comparable to future studies. Second, data were extracted from a database that contained information on all women with an SCI followed in the Clinic for SCI, Rigshospitalet, which covers nearly half of the female SCI population living in Denmark. This design is unique as most other SCI studies were conducted in selected groups of SCI persons who were referred to or treated at tertiary clinics. Nonetheless, the study also has some limitations. First, if a woman with SCI had not visited a clinic between 2010 and 2016, she was not included in this study. As all persons with SCI in the eastern part of Denmark are invited to attend followup visits in the clinic every second year, it is assumed that most of the population was seen in the clinic in this period; however, it is a limitation that the complete list of women with SCI living in the eastern part of Denmark was not obtainable. Second, $17 \%$ of the identified population had missing data on the UI question and were excluded. The excluded women were comparable to the included women regarding the type of injury, but were of older age. As age is known to increase the risk of UI in women [17], the prevalence of UI could be underestimated in this study. Second, the study was conducted on data from a database where mistakes could occur during several processes, for example, when the information was entered in the database or during extraction of the data. To investigate the magnitude of this problem, the authors evaluated the answers to the condom-catheter question, but the lack of positive answers suggests a good accuracy of the database. Third, there were no information on UI prior to injury or body mass index and parity, which are known risk indicators of UI, nor were we able to distinguish between the types of UI based on urodynamic investigations.

As the majority of the included women had an incomplete injury, and $78 \%$ were classified with an AIS D, it could be argued that there is an overrepresentation of incomplete injuries in this study. On the other hand, as this study included all women with an SCI during 1999-2016, who attended a regular follow-up visit in our clinic during 2010-2016, the study population merely reflects the group of women with a newly sustained SCI living in Denmark. This is in accordance with studies demonstrating a tendency towards an increase in incomplete injuries over time, with the highest proportion of incomplete injuries among the non-traumatic injuries [26, 27].

In conclusion, half of the women with an SCI are urinary incontinent, of whom the majority experience UI daily, and UI is associated with impaired mobility, unmarried/ non-cohabitation status, and reduced QoL. Clinicians should bear in mind that UI is a prevalent and severe problem in women with SCI that can potentially be treated at a specialized urogynecological or urological department in collaboration with SCI-specialized clinicians. It would be interesting for future studies to evaluate urogynecological treatments of UI in women with SCI.

Author contributions ME was responsible for designing and planning of the study, data acquisition, data analysis and interpretation, and writing the report. NK contributed to the design and planning of the study, interpretation of the results, and providing feedback on the report. FB-S contributed to the design and planning of the study, data acquisition, interpretation of the results, and proving feedback on the report.

\section{Compliance with ethical standards}

Conflict of interest The authors declare that they have no conflict of interest. 


\section{References}

1. Wyndaele JJ, Kovindha A, Madersbacher H, Radziszewski P, Ruffion A, Schurch B, et al. Neurologic urinary incontinence. Neurourol Urodyn. 2010;29:159-64.

2. Bloemen-Vrencken JH, Post MW, Hendriks JM, De Reus EC, De Witte LP. Health problems of persons with spinal cord injury living in the Netherlands. Disabil Rehabil. 2005;27:1381-9.

3. Cetinel B, Onal B, Turegun FA, Erdogan S. Urologic health condition of spinal cord-injured patients living in turkey. Spinal Cord. 2014;52:302-6.

4. Lee JS, Kim SW, Jee SH, Kim JC, Choi JB, Cho SY, et al. Factors affecting quality of life among spinal cord injury patients in korea. Int Neurourol J. 2016;20:316-20.

5. Bjornshave Noe B, Mikkelsen EM, Hansen RM, Thygesen M, Hagen EM. Incidence of traumatic spinal cord injury in denmark, 1990-2012: a hospital-based study. Spinal Cord. 2015;53:436-40.

6. Martins F, Freitas F, Martins L, Dartigues JF, Barat M. Spinal cord injuries-epidemiology in portugal's central region. Spinal Cord. 1998;36:574-8.

7. New PW, Sundararajan V. Incidence of non-traumatic spinal cord injury in victoria, australia: a population-based study and literature review. Spinal Cord. 2008;46:406-11.

8. van den Berg ME, Castellote JM, Mahillo-Fernandez I, de PedroCuesta J. Incidence of nontraumatic spinal cord injury: a Spanish Cohort Study (1972-2008). Arch Phys Med Rehabil. 2012;93:325-31.

9. Biering-Sorensen F, Craggs M, Kennelly M, Schick E, Wyndaele JJ. International lower urinary tract function basic spinal cord injury data set. Spinal Cord. 2008;46:325-30.

10. Biering-Sorensen F, Gregersen H, Hansen HV, Nielsen L, Ranneries P, Rolfsager $\mathrm{K}$, et al. Multidisciplinary electronic medical record and clinical database all in one. Scibase. Ugeskr Laege. 2001;163:3207-12.

11. Maynard FM Jr, Bracken MB, Creasey G, Ditunno JF Jr, Donovan WH, Ducker TB, et al. International standards for neurological and functional classification of spinal cord injury. American Spinal Injury Association. Spinal Cord. 1997;35:266-74.

12. Levi R, Ertzgaard P. Quality indicators in spinal cord injury care: a Swedish Collaborative Project. The Swedish Spinal Cord Injury Council 1998. Scand J Rehabil Med Suppl. 1998;38:1-80.

13. Kirshblum SC, Burns SP, Biering-Sorensen F, Donovan W, Graves DE, Jha A, et al. International standards for neurological classification of spinal cord injury (revised 2011). J Spinal Cord Med. 2011;34:535-46.

14. DeVivo M, Biering-Sorensen F, Charlifue S, Noonan V, Post M, Stripling $\mathrm{T}$, et al. International spinal cord injury core data set. Spinal Cord. 2006;44:535-40.
15. New PW, Marshall R. International spinal cord injury data sets for non-traumatic spinal cord injury. Spinal Cord. 2014:52:123-32.

16. Charlifue S, Post MW, Biering-Sorensen F, Catz A, Dijkers M, Geyh S, et al. International spinal cord injury quality of life basic data set. Spinal Cord. 2012;50:672-5.

17. Hannestad YS,Rortveit G,Sandvik H,Hunskaar S, Norwegian EsEolitCoN-T. A community-based epidemiological survey of female urinary incontinence: The Norwegian Epincont Study. Epidemiology of incontinence in the County of Nord Trondelag. $\mathrm{J}$ Clin Epidemiol. 2000;53:1150-7.

18. Hunskaar S, Lose G, Sykes D, Voss S. The prevalence of urinary incontinence in women in four european countries. BJU Int. 2004;93:324-30.

19. Schreiber Pedersen L, Lose G, Hoybye MT, Elsner S, Waldmann A, Rudnicki M. Prevalence of urinary incontinence among women and analysis of potential risk factors in Germany and Denmark. Acta Obstet Gynecol Scand. 2017;96:939-48.

20. Hansen RB, Biering-Sorensen F, Kristensen JK. Urinary incontinence in spinal cord injured individuals $10-45$ years after injury. Spinal Cord. 2010;48:27-33.

21. Park SE, Elliott S, Noonan VK, Thorogood NP, Fallah N, Aludino A, et al. Impact of bladder, bowel and sexual dysfunction on health status of people with thoracolumbar spinal cord injuries living in the community. $\mathrm{J}$ Spinal Cord Med. 2017;40:548-59.

22. Komesu YM, Schrader RM, Ketai LH, Rogers RG, Dunivan GC. Epidemiology of mixed, stress, and urgency urinary incontinence in middle-aged/older women: the importance of incontinence history. Int Urogynecol J. 2016;27:763-72.

23. Liu CW, Attar KH, Gall A, Shah J, Craggs M. The relationship between bladder management and health-related quality of life in patients with spinal cord injury in the UK. Spinal Cord. 2010;48:319-24.

24. Valtonen K, Karlsson AK, Siosteen A, Dahlof LG, Viikari-Juntura E. Satisfaction with sexual life among persons with traumatic spinal cord injury and meningomyelocele. Disabil Rehabil. 2006;28:965-76.

25. Stickley A, Santini ZI, Koyanagi A. Urinary incontinence, mental health and loneliness among community-dwelling older adults in ireland. BMC Urol. 2017;17:29.

26. Devivo MJ. Epidemiology of traumatic spinal cord injury: trends and future implications. Spinal Cord. 2012;50:365-72.

27. New PW, Reeves RK, Smith E, Townson A, Eriks-Hoogland I, Gupta A, et al. International retrospective comparison of inpatient rehabilitation for patients with spinal cord dysfunction epidemiology and clinical outcomes. Arch Phys Med Rehabil. 2015;96:1080-7. 